\title{
ГИДРОГЕОЛОГИЯ
}

УДК 502.51:556.3(470.5)

\section{О формировании водного стока на осваиваемых территориях}

\author{
А.Я. Гаев, В.Э. Бикитеев, И.В. Куделина, Т.В. Леонтьева, \\ Л.А. Кременцова \\ Оренбургский государственный университет. Институт экологических про- \\ блем гидросферы при ОГУ, 460018, Оренбург, пр. Победы, 13. Email: \\ gayev@mail.ru \\ (Статья поступила в редакиию 7 января 2013 г.)
}

\begin{abstract}
Тенденция повсеместного истребления лесных насаждений, особенно в лесостепных и степных районах, включая Оренбуржье, ведет к истощению водных ресурсов по причине резкого роста неравномерности стока. Одновременно усиливаются негативные геодинамические процессы, приводящие к затоплению и подтоплению обширных территорий. Для снижения интенсивности негативных геодинамических процессов и борьбы с их катастрофическими последствиями рекомендуется приступить к широкомасштабным лесонасаждениям и регулированию стока путем обоснованного гидротехнического строительства с соответствующим комплексом водоохранных мероприятий.

Ключевые слова: негативные геодинамические прочессы, вырубка лесов, водный сток.
\end{abstract}

Исследования выполнены на примере Оренбургской области, которая в гидрогеологическом отношении приурочена в западной своей части к Волго-Камскому артезианскому бассейну, на востоке - к Уральской гидрогеологической складчатой области. На западе территории есть нефтегазовые месторождения в пределах таких геологических структур, как ВолгоУральская антеклиза и северное обрамление Прикаспийской синеклизы. В пределах южной части Уральской гидрогеологической складчатой области развитие экономики связано с разработкой месторождений твердых полезных ископаемых: медно-колчеданных, золоторудных, силикатного никеля, каменного и бурого угля, строительных материалов и прочее. Освоение территории Оренбуржья сопровож- дается вырубкой лесов с уменьшением лесистости, увеличением количества нарушенных земель, отвалов горных пород и некондиционных руд. Освоение территории такого рода ведет к усилению негативных геодинамических процессов: разрушительной деятельности поверхностных водотоков, уплотнению грунтов зоны аэрации с уменьшением их пористости и водонасыщенности и, как следствие, вызывает изменение водного баланса территории.

Среднегодовое за многолетие количество осадков в Оренбуржье в $2 \div 3$ раза уступает величине испаряемости. Сумма осадков в г. Оренбурге изменяется от 464 (2001) до 332 мм (2002). Выявлены месяцы с самым большим количеством осадков (61 мм в июне) и самым маленьким 
(13,1 мм в августе), рассчитанными по средним многолетним значениям.

За последнее столетие резко возросло количество аварий и катастрофических ситуаций, связанных с водным стоком, загрязнением и истощением природных вод [11]. Достаточно упомянугь катастрофические наводнения на Дальнем Востоке и в Крымске. Резкое увеличение рисков таких событий обусловлено исключительно техногенными геологическими процессами в связи с нарастающими негативными геодинамическими процессами из-за нерационального природопользования. В качестве примера приведем бассейн р. Урал в пределах Оренбургской области, где за последние полвека участились наводнения с затоплением и подтоплением обширных территорий. Несмотря на то, что среднегодовое за многолетие количество осадков в 2-3 раза уступает величине испаряемости, в последние десятилетия участились разрушительные наводнения, подтопления застроенных территорий, широкие масштабы получили процессы эрозии, оврагообразования, загрязнения и истощения природных вод. По данным государственного контроля, большинство водозаборов подземных вод и все водоемы области не отвечают требованиям санитарных норм. Учитывая, что качество подземных вод значительно выше, чем в поверхностных водоемах, еще в советский период было принято решение о хозяйственно-питьевом водоснабжении за счет подземных водоисточников.

Тем не менее и сегодня хозяйственнопитьевое водоснабжение в некоторых районах области, например, в пос. Первомайский Оренбургского района и Энергетик Новоорского района, г. Ясном производится за счет поверхностных вод, в значительной степени загрязненных и для питья не пригодных. Это касается и Ириклинского водохранилища на Урале, аккумулирующего более 3 км$^{3}$ воды. Три четверти объемов этой воды $\left(80 \mathrm{~m}^{3} / \mathrm{c}\right)$ направляется на охлаждение агрегатов Ириклинской ГРЭС и около 9 тыс.м ${ }^{3} /$ сут тратится на водоснабжение пос. Энергетик и самой ГРЭС. Вода предварительно осветляется с использованием соединений серно-кислого алюминия и хлорируется. После подготовки в воде синтезируются вредные хлорорганические и ферросоединения, выпадающие в осадок на внутренних стенках водоводов, эксплуатируемых более 40 лет. Они засоряют и внутренние органы людей, обусловливая высокую заболеваемость населения.

Хозяйственно-питьевое водоснабжение населения области на 88,8 \% производится за счет пресных подземных вод преимущественно аллювиального водоносного горизонта $[5,6]$. По площади территории в области доминирует бассейн р. Урал, а северо-запад области приурочен к Волжскому бассейну (рисунок). На крайнем востоке расположен небольшой по площади участок бассейна р. Тобол и небольшая область внутреннего стока с озерами Шелкар-Ега-Кара, Жетыколь и др. Физико-географические и гидрологогидрогеологические условия формирования природных вод области исключительно сложные.

В равнинной, платформенной части области мощность и объемы аллювиальных отложений, содержащих пресную воду, значительно больше, чем в горноскладчатых районах, где распространены трещинные воды зоны коры выветривания, трещинно-жильные воды в зонах тектонических нарушений и трещиннокарстовые воды.

Техногенное воздействие на природные воды оказывают различные предприятия: промышленные, горнодобывающие, сельскохозяйственные, энергетические, гидротехнические, транспортные, а также селитебные, или бытовые, и военные источники. На формирование химического состава вод влияют процессы растворения гипсово-соленосных отложений, выноса на поверхность глубинных флюидов, ореолы рассеяния от неразрабатываемых полезных ископаемых и некондиционные воды и рассолы [1]. Вокруг определенных источников загрязнения вод формируются 
ареалы и потоки рассеяния определенных загрязняющих веществ. С ростом степени урбанизации территории среди загрязняющих водоемы и водозаборы веществ возрастает роль супертехнофильных элементов. При анализе материалов по вод- ному стоку и качеству воды в ретроспективном плане хотя бы на протяжении 5060 лет четко просматриваются такие тенденции, как увеличение неравномерности стока, ухудшение качества воды в

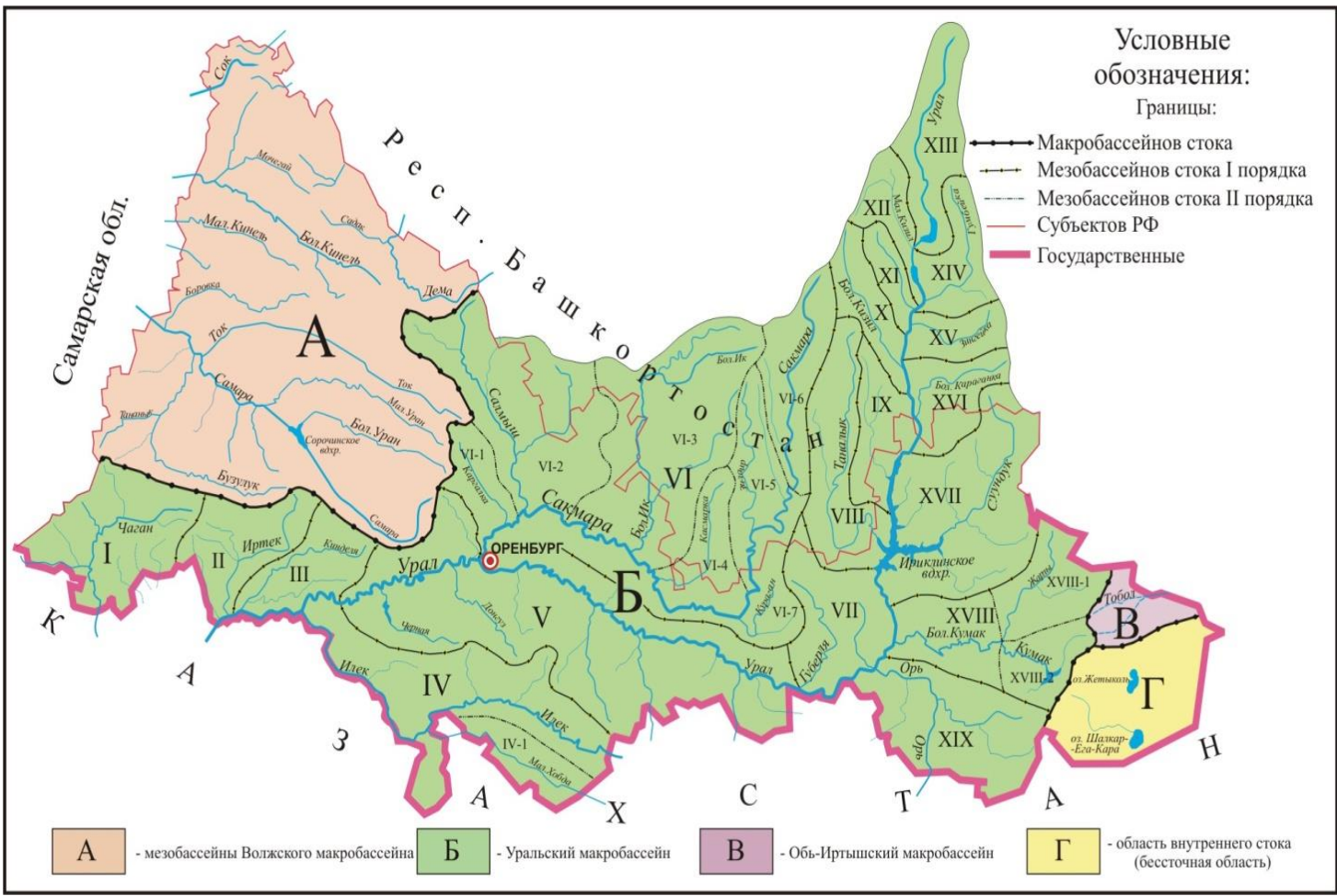

Бассейны стока Оренбургской области. А - мезобассейны Волжского макробассейна. Б Уральский макробассейн стока. В - Тобольский мезобассейн стока. Г- область внутреннего стока (бессточная область). Мезобассейны Уральского макробассейна стока первого порядка: I - Чаганский; II - Иртекский; III - Кинделинский; IV - Илекский (мезобассейн второго порядка IV-1 - Малохобдинский); $V$ - микро- и мезобассейны стока временных и пересыхающих водотоков; VI - Сакмарский (мезобассейны второго порядка: VI-1 - Каргалкинский; VI-2 - Салмылиский; VI-3 - Большеикский; VI-4 - Касмаркский; VI-5 - Зилаирский; VI-6 - Баракальский; VI-7 - Крепостнозилаирский; VI-8 - Верхнесакмарский; VI-9 - Кураганский); VII - Губерлинский; VIII - Таналыкский; IX - Уртазымский; X - Большекизильский; XI - Янгельский; XII - Малокизильский; XIII - Верхнеуральский; XIV - Гумбейский; XV - Зингейский; XVI - Большекараганский; XVII - Суундукский; XVIII - Большекумакский (мезобассейны второго порядка: XVIII-1 - Жарлькский; XVIII-2 - Кумакский); ХIX - Орьский

водоемах и водозаборах, исчезновение рыбных ресурсов в водоемах. Особенно резко возросла степень заиления водоемов и активизировались негативные геодинамические процессы. Причины этих явлений связаны с распашкой речных пойм, что в довоенной истории считалось недопустимым. Это началось в период войны, когда стоял вопрос о жизни и смерти наших народов. Все силы были направлены на выживание и победу. Но практика распашки пойменных земель сохранилась и сегодня, что служит одной из причин усиления негативных геодинамических процессов. Еще одна причина - строительство временных плотин на реках для организации водопоя скота в летний период. Эти многочисленные мелкие плотины в паводок размываются, и водоемы интенсивно заиляются. С 
освоением пойм начали вырубать пойменные и не только пойменные леса. О связи леса и воды писали еще П.И. Рычков, С.Т. Аксаков, профессор Казанского университета Эверсман и др. [14]. По свидетельству П.И. Рычкова, экспедиция И.К. Кирилова сплавлялась по р. Урал от современного Верхнеуральска к современному Орску, который она и основала как Оренбург 1 в 1736 г., на пароходах. По свидетельству П.И. Рычкова, пароходы ходили по Уралу, пока не пострадали леса по его берегам.

Очевидно, что от устойчивости водного режима в степных и лесостепных районах зависит урожайность посевных площадей, а сама устойчивость жизни зависит от лесистости территории, которая в последние десятилетия резко уменьшается, что стимулирует негативные геодинамические процессы. Эта связь была понятна правительству СССР и в тяжелый послевоенный период. Несмотря на все трудности, в 1949 г. начались широкомасштабные посадки лесов и была создана лесополоса гора Вишневая - Каспийское море. Эти работы позитивно отразились на гидрогеологических условиях территории, водном стоке, качестве воды и продуктивности водоемов.

Аналогичные геодинамические процессы характерны и для таежных районов нашей страны, где на больших территориях идет вырубка лесов.

Так, еще современники Петра I И.Т. Посошков (1652-1726) и В.Н. Татищев (1686-1750) в своих работах подчеркнули необходимость охраны и рационального использования лесных ресурсов [9]. Изучению лесов и природных вод России в XVIII в. посвящены работы П.И. Рычкова и участников академических экспедиций (под руководством Палласа, Лепехина и др.). Основы научного знания о связи леса и воды заложил М.В. Ломоносов (1711$1765)$ в своей записке «Мнение о учреждении государственной коллегии» (1760). Эта тема продолжала разрабатываться экспедициями, возглавляемыми К.Э. фон Бэром и П.И. Кёппенем, в губер- нии Верхнего Поволжья в 1837-1840 гг. [9]. Они указали, что истощение родников и обмеление Волги связано с истреблением лесов. Актуальность вопроса, поднятого предшествующими исследователями, о связи водного стока с залесенностью территории в настоящее время значительно возросла в связи с участившимися случаями затопления и подтопления обширных территорий и усилением негативных динамических процессов. Так, К.Д. Мухамедшин с коллегами отмечают рост неравномерности водного стока в бассейне Верхней Волги в связи с массовой вырубкой лесов [10]. Ту же мысль развивает Н.К. Кожевникова, доказывая, что на формирование паводка влияет состояние лесной растительности [8]. После вырубки лесов паводки исключительно активизируются и восстанавливаются до естественного состояния только через 15-30 лет, как и вырубленные леса, но их частота возрастает. Этот процесс проявляется в общепланетарном масштабе, поскольку планета ежегодно теряет не менее одного миллиона гектаров лесов. Суть этих процессов чисто гидрогеологическая. При вырубке лесов резко уменьшается скважность пород в зоне аэрации из-за отмирания и деградации корневой системы растений, проникающей на 10 м и более в глубь земли. С уменьшением скважности резко падает объем коллекторов не только в зоне аэрации, но и в гидродинамических зонах сезонного колебания и постоянного горизонтального стока. В результате существенно уменьшается подземная составляющая водного стока территории. Изменяется водный баланс территории, основную роль приобретает поверхностный сток, интенсивность которого возрастает в разы, а временной период водного стока резко сокращается. Водные потоки приобретают исключительную разрушительную силу. Резко возрастают негативные геодинамические процессы, что наблюдается в настоящее время не только в бассейне р. Урал, на Дальнем Востоке, но и на Северном Кавказе, например, в г. Крымске. Такого рода процессы становят- 
ся тенденцией современного природопользования.

Еще одним примером сельскохозяйственного освоения земель, ранее покрытых лесами, служат районы Алтая в Западной Сибири, в частности бассейн р. Алей [13]. По официальным данным 2000-2007 гг., в сельскохозяйственный оборот включено до 77 \% земель и свыше половины из них распаханы. Существует прямая связь речного стока с распаханностью территории, и нельзя не отметить, что изменение его, прежде всего связано, с подземной составляющей водного стока.

В настоящее время в условиях интенсификации негативных геодинамических процессов делаются попытки чистить русла рек, укреплять берега, строить защитные дамбы при наводнениях, разводить рыбу в загрязненных водоемах и пр. Прежде чем принимать ответственные решения, требующие больших финансовых затрат, необходимо усвоить простую истину, которую высказал еще Гиппократ. Он отметил, что любую болезнь можно излечить только в том случае, если будет выявлена и устранена основная причина, ее вызывающая.

Основными причинами наводнения, затопления и подтопления обширных территорий служат негативные геодинамические процессы, связанные с изменением структуры грунтов в зоне активного водообмена. Негативные процессы имели место и в естественной природной обстановке, но особенно усилились при вмешательстве человека в природный комплекс. Это ощущается во всех регионах нашей страны. Ведущим фактором этих негативных процессов является уничтожение лесных насаждений на осваиваемых территориях и резкое снижение общей лесистости, особенно в лесостепных и степных районах. Там, где есть лесные насаждения, процессы деградации грунтов в зоне активного водообмена практически отсутствуют и водный баланс территории сохраняется почти стабильным. Доля инфильтрационных подземных вод возрастает, по сравнению с нарушенными тер- риториями, в разы, и резко уменьшается доля кратковременного, разрушительного поверхностного стока. Лесополоса гора Вишневая - Каспийское море ныне запущена и нуждается в реконструкции. Но и сегодня она еще служит людям, сдерживая нарастающую деградацию грунтов в зоне активного водообмена и гидросферы региона.

Необходимо на федеральном уровне вернуться к широкомасштабным лесопосадкам по долинам крупных рек, расстаться с порочной практикой распашки земель в поймах. Мероприятия по снижению интенсивности негативных геодинамических процессов должны носить планомерный и комплексный характер. Наряду с широкомасштабными лесопосадками, прежде всего в поймах рек, оврагах и неудобьях, необходимо приступить к строительству малых плотин по проектам малой энергетики. Надо вспомнить, что до революции только в Оренбургской губернии существовало более двух тысяч малых плотин, добротно и профессионально построенных российскими гидротехниками. При комплексных мероприятиях, включающих лесопосадки и гидротехническое строительство, можно тратить средства на очистку речных русел и укрепление берегов. В противном случае эти работы необходимо будет возобновлять каждые 2-3 года, и каждый раз начинать все с начала, поскольку негативные геодинамические процессы сведут их к нулю. Поэтому очевидна целесообразность траты денег и огромных усилий на расчистку русел рек только в комплексе с широкомасштабными лесопосадками, с новым подходом к землеустройству, с ликвидацией распашки земель в поймах и продуманным профессиональным гидротехническим строительством, с полным запретом создания временных плотин для водопоя скота и пр. Основная стратегия природопользования должна быть направлена на снижение интенсивности негативных геодинамических процессов.

Одновременно необходимо ревизовать состояние экосистемы на всех осваивае- 
мых территориях. Опасность заключается в том, что в регионах появилось огромное количество источников загрязнения природных вод и окружающей среды. Кроме того, на большом количестве нарушенных площадей формируются некондиционные природные воды. Следует ревизовать все гидротехнические сооружения, не только существующие сегодня, но и существовавшие. На освоенных территориях имеются десятки тысяч горных выработок, глубоких скважин, которые не эксплуатируются и не ликвидированы должным образом. Они, как правило, влияют на формирование подземных и поверхностных вод путем перетоков более глубоких флюидов к поверхности земли. Нельзя не отметить, что сегодня существует немало прудов, размываемых в паводки и половодья. Они регулярно намываются на летний период для водопоя скота и размываются весной, заиляя речные бассейны. Пока не будет прекращена эта порочная практика и плотины не будут строиться по профессиональным гидротехническим проектам, процессы заиления речной сети будут усиливаться.

Далеко не все источники загрязнения, к сожалению, можно ликвидировать. Есть немало объектов, жизненно необходимых народному хозяйству, но технологии на этих объектах нуждаются в существенном совершенствовании. Среди отечественных руководителей стала модной покупка за рубежом технологий очистки воды, в основе которых лежат российские разработки геохимических барьеров одного из корифеев отечественной геохимии - Александра Ильича Перельмана [12]. В развитие идей Перельмана в Оренбургском госуниверситете с участием лауреата Государственной премии профессора В.Д. Бабушкина [1] разработаны технологии комплексных гидродинамических и геохимических барьеров [3-5]. Широкое применение барьерных технологий на водоемах и водозаборах должно стать одним из важнейших мероприятий по предотвращению загрязнения водных ресурсов. Во многих странах оно уже привлекло внимание специалистов и внедрено в комплекс геологоразведочных работ, все шире используется в конкретных проектax.

Таким образом, в комплекс мероприятий по водо- и природопользованию необходимо включить:

1. Обширные лесопосадки, которые должны постоянно расширяться и к концу XXI столетия достигнуть $10 \%$ площади лесостепных и степных районов страны, уровня середины XVIII в.

2. Ревизии состояния экосистемы территорий с оценкой гидротехнических и горно-геологических объектов.

3. Системы защиты водоемов и водозаборов от загрязнения на основе применения барьерных технологий.

4. Создание единой системы мониторинга.

\section{Библиографический список}

1. Бабушкин В.Д., Гаев А.Я., Гаиков В.Г. и $\partial p$. Научно-методические основы защиты от загрязнения водозаборов хозяйственнопитьевого назначения / Перм. гос. ун-т. Пермь, 2003. 264 c.

2. Гаев А.Я., Алферов И.Н., Лихненко Е.В., Локоткова Н.С. Пат. № 47914 РФ. Установка совмещенного вертикального и горизонтального дренажа при локализации загрязненных флюидов / Заявлено 30.05.2005. Опубликовано 10.09.05. Бюл. №. 25 .

3. Гаев А.Я., Алферов И.Н., Лихненко Е.В., Локоткова Н.С. Пат. № 55382 РФ. Устройство барьерного типа перед водо-забором подземных вод / Заявлено 17.11.2005. Опубликовано 10.08.06. Бюл. №. 22.

4. Гаев А.Я. Кузнеиова Е.В., Алферов И.Н., Фоминых А.А., Почечун В.А. Пат. № 2289658 РФ. Способ локализации загрязнений при эксплуатации водозаборов хозяйственно-питьевого назначения / Заявлено 11.10.2004. Опубликовано 20.12.06. Бюл. №35.

5. Информационные бюллетени о состоянии геологической среды на территории Оренбургской области в 1997-2010 гг. Оренбург: ОАО «Вотемиро», 1997-2010.

6. Информационные бюллетени. О состоянии поверхностных водных объектов, во- 
дохозяйственных систем и сооружений на территории Оренбургской области / Правительство Оренбургской обл. Оренбург, 2008-2011.

7. Клейменова И.Е., Беликова Н.Г., Гаев А.Я. Пат. 66702 РФ. Система для очистки загрязненного нефтью или нефтепродуктом грунта/Заявлено 02.05.2007. Опубликовано 27.09.07. Бюл. № 27.

8. Кожевникова Н.К. Водный режим горных лесных бассейнов в период циклонической активности // Вестник Краснодарского ГАУ. 2008. № 6. С. 70-79.

9. Лоскутова М.В. «Влияние лесов на обмеление рек есть только недоказанная гипотеза»: прикладная наука и государственная политика по управлению лесным хозяйством Российской империи второй четверти XIX века // Историкобиологические исследования. 2012. Т. 4,
№ 1. C. 9-32

10. Мухамедшин К.Д. Влияние сплошных концентрированных рубок на водоохранно-защитные функции лесов ВетлужскоУнженской равнины // Лесной вестник. 2003. № 3. C. 85-93.

11. Осипов В.И. Опасные природные процессы - стратегические риски России // Бюл. Комиссии по изучению четвертичного периода. М.: ГЕОС, 2008. № 68. С. 5-9.

12. Перельман А.И. Геохимия. М.: Высшая школа, $1989.528 \mathrm{c}$.

13. Стоящева Н.В. Лесные насаждения как фактор устойчивого речного стока в бассейне реки Алей // Изв. Самар. науч. центра РАН. 2010. Т. 12, № 1(3). С. 897-900.

14. Чибилев А.А. Бассейн Урала: история, география, экология / УрО РАН. Екатеринбург, 2008. 312 c.

\title{
About Formation of a Water Drainage System on the Territories under Development
}

\author{
A.Y. Gayev, V.E. Bikiteev, I.V. Kudelina, T.V. Leontyeva, and \\ L.A. Krementsova \\ Orenburg State University, Institute of Ecological Problems of the Hydrosphere \\ of OSU. 460018, Orenburg, Pobeda St., 13. Email:gayev@mail.ru
}

The trend of widespread destruction of forest plantations, especially in the foreststeppe and steppe regions, such as the Orenburg region, leads to the depletion of water resources due to an increase of flow non-uniformity. Simultaneously, the strengthened negative geodynamic processes lead to flooding and waterlogging of large areas. A widespread afforestation and run-off regulation by working out the reasonable hydro construction program including the effective water conservation measures were suggested for reducing the intensity of negative geodynamic processes and mitigating the catastrophic consequences.

Keywords: negative geodynamic processes, deforestation, drainage, water conservation.

\section{References}

1. Babushkin V.D., Gayev A.Ya., Gatskov V.G. et al. 2003. Nauchno-metodicheskiye osnovy zashchity ot zagriazneniya vodozaborov khoziaystvenno-pityevogo naznacheniya [Scientific methodological basics of protection against pollution of intakes of technical and drinking water]. Perm, Perm University, $264 \mathrm{p}$.

2. Gayev A.Ya., Alferov I.N., Likhnenko E.V., and Lokotkova N.S. Patent № 47914 RF. Unit of combined vertical and horizontal drainage for localization of contaminated fuids. Filing 30.05.2005. Published: Bull. 25. 10.09.05. Priority 30.05.2005. 
3. Gayev A.Ya., Alferov I.N., Likhnenko E.V., and Lokotkova N.S. Patent № 55382 RF. Barrier type unit before the groundwater intake. Filing 17.11.2005. Published: Bull. №. 22. 10.08.06. Priority 17.11.2005

4. Gayev A.Ya., Kuznetsova E.V., Alferov I.N., Fominykh A.A., and Pochechun V.A. Patent № 2289658 RF. Method of localization of the contamination during use of the intake of technical and drinking water. Filing 11.10.2004. Published: Bull. №. 35. 20.12.06. Priority 11.10.2004.

5. Informatsionnye byulleteni. $\mathrm{O}$ sostoyanii geologicheskoy sredy na territorii Orenburgskoy oblasti v 1997-2010 gg. [Information bulletines. About the environmental condition at the Orenburg region]. Orenburg, Votemiro, 1997-2010.

6. Informatsionnyie byulleteni. $\mathrm{O}$ sostoyanii poverkhnostnykh vodnykh obyektov, vodokhozyaystvennykh system i sooruzheniy na territorii Orenburgskoy oblasti [Information bulletines. About condition of the surface water facilities, hydro-engineering systems and structures at the Orenburg region]. Orenburg, Orenburg gov. Publishing, 20082011.

7. Kleymenova I.E., Belikova N.G., and Gayev A.Ya. Patent № 66702 RF. Sistema dlya ochistki zagryaznennogo neftiyu ili nefteproduktom grunta [System of treatment of the ground contaminated with petroleum or petroleum product]. Filing 02.05.2007. Published: Bull. № 27. 27.09.07 Priority 02.05. 2007.

8. Kozhevnikova N.K. 2008. Vodnyy rezhim gornykh lesnykh basseynov v period tsiklicheskoy aktivnosti [Water regime of mountain forest drainage basins in conditions of cyclic activity]. Vestnik KrasGAU, 6:70-79.

9. Loskutova M.B. 2012. "Vliyaniye lesov na obmeleniye rek est tolko nedokazannaya gipoteza»: prikladnaya nauka i gosudarstvennaya politika po upravleniyu lesnym khozyaystvom Rossiyskoy imperii vtoroy chetverti XIX veka ["Influence of forestry to the river shoaling is unproved hypothesis only": applied science and state policy on the forestry management of Russian Empire in XIX century]. Istoriko-biologicheskiye issledovaniya, 4(1):9-32.

10. Mukhamedshin K.D. 2003. Vliyaniye sploshnykh kontsentrirovannykh rubok na vodookhranno-zashchitnye funktsii lesov Vetluzhsko-Unzhenskoy ravniny [Impact of the complete concentrated woodcutting on the water protective functions of forest of the Vetluga-Unzha Plain]. Lesnoy vestnik, 3: 85-93.

11. Osipov V.I. 2008. Opasnye prirodnye protsessy - strategicheskiye riski Rossii [Natural hazards as the strategic risks of Russia]. Bull. Komissii po izucheniyu chetvertichnogo perioda, 68:5-9.

12. Perelman A.I. 1989. Geokhimiya [Geochemistry]. Moscow, Vysshaya shkola. 528 p.

13. Stoyashcheva N.V. 2010. Lesnyie nasazhdeniya kak factor ustoychivogo rechnogo stoka v basseyne reki Aley [Forest plantation as a factor of sustainable run-off in the basin of Aley River]. Izvestiya Samarskogo nauchnogo tsentra RAS, T. 12, no. 1(3):897-900.

14. Chibilev A.A. 2008. Basseyn Urala: istoriya, geografiya, ecologiya [Basin of Ural River: history, geography, ecology]. Yekaterinburg, UB RAS. 312 p. 